\title{
A CIÊNCIA EM LUIS ANTÓNIO VERNEY: ALGUMAS CONSIDERAÇÕES
}

\author{
THE SCIENCE IN LUIS ANTONIO VERNEY: SOME CONTEMPLATION
}

\author{
(1D) Verônica Alves dos Santos Conceição \\ Doutoranda em Educação, Universidade Tiradentes - Unit \\ Aracajú, Sergipe - Brasil \\ veronica.alves604@gmail.com \\ Cristiane de Magalhães Porto \\ Pós-doutorado em Educação, Universidade Tiradentes - Unit \\ Aracajú, Sergipe - Brasil \\ crismporto@gmail.com
}

Resumo: O estudo aborda a Ciência a partir do pensamento de Luis António Verney (17131792) em sua obra $\mathrm{O}$ Verdadeiro Método de Estudar (1746). Tem por objetivo analisar como a Ciência se apresenta na proposta verneyniana de reformulação do sistema de ensino português, no século XVIII, ao tempo em que dialoga com as concepções emergentes de Ciência na Europa Oitocentista e com a tradição religiosa, católica, que marca a formação do autor. O texto se constitui como uma revisão bibliográfica de base teórica. Como resultado, constata-se que os aspectos internos da obra refletem o contexto socioeconômico e o cultural da Europa alinhados a formação religiosa de Verney. Conclui-se que o desenho de educação pensada para Portugal nasce da coexistência da Filosofia, da Ciência e da Religião.

Palavras-chave: Ciência moderna. Método científico. Verdade. Companhia de Jesus. Congregação do oratório.

Abstract: The study is based on the thought of Luis Antonio Verney (1713-1792) in his work The True Method of Study (1746). Its purpose is to analyze how science is presented in the Verneynian proposal to reformulate the Portuguese education system in the 18th century, at a time when it is in dialogue with the emerging conceptions of science in Eight century Europe and with the religious, Catholic tradition that marks the author's formation. The text is constituted as a theoretically based bibliographical revision. As a result, it is noted that the internal aspects of the work reflect the socio-economic and cultural context of Europe aligned with Verney's religious formation. It is concluded that the design of education thought for Portugal is born from the coexistence of Philosophy, Science and Religion.

Keywords: Modern science. Scientific method. truth. Company of Jesus. Congregation of the oratory.

\section{Para citar - (ABNT NBR 6023:2018)}

CONCEIÇÃO, Verônica Alves dos Santos; PORTO, Cristiane de Magalhães. A ciência em Luis António Verney: algumas considerações. Eccos - Revista Cientifica, São Paulo, n. 55, p. 1-18, e13274, out./dez. 2020. Disponível em: https://doi.org/10.5585/eccos.n55.13274. 


\section{Introdução}

A palavra Ciência, tal como a compreendemos, conceituamos e usamos, foi cunhada no século XIX, portanto a concepção de Ciência que temos hoje não existia no início da Idade Moderna. É por isso que, falar de Ciência a partir dos critérios da contemporaneidade, como se ela sempre existisse nessa moldura, constitui um engano. Afinal, o que existia nos períodos que antecederam o século XIX, inclusive durante a Revolução Científica? Para Henry (1998), o que existia era uma Filosofia Natural que pretendia descrever e explicar o mundo em sua totalidade. A expressão 'Filosofia Natural' era utilizada para explicar a compreensão dos fenômenos do mundo físico. Essa Filosofia somada às técnicas desenvolvidas permitiam a criação de novos conhecimentos e novas práticas que formavam blocos, próximos do que conhecemos hoje como disciplinas científicas.

Com a passar dos anos, segundo Henry (1998), o termo Filosofia Natural se agregou a outras descobertas e se transformou no que entendemos como Ciência e seus termos correlatos, dentre eles, a Revolução Científica e a Ciência Moderna. De fato, a historiografia científica, nas suas várias vertentes, parece reconhecer a presença da Filosofia na construção dos fundamentos da Ciência, na definição dos métodos científicos e na constituição dos seus objetivos. Entretanto, qual o lugar que a Filosofia ocupa na Ciência ainda é tema de controvérsia.

Para alguns historiadores, a Ciência e a Filosofia se separaram a partir da Modernidade porque a Filosofia não atende a uma exigência fundamental da Ciência Moderna: a produção de provas que tornem verdadeiros os conhecimentos produzidos. Desde a Modernidade, compreendemos que conhecimento científico é aquele que produz provas e resultados. Ao passo que, o pensamento filosófico se empodera na capacidade de se refazer sem se preocupar com a comprovação do seu resultado. Nessa linha de pensamento, Ciência e Filosofia se confrontam. De outro lado, há a compreensão de alguns historiadores de que a Teologia, a Filosofia e a Ciência formam uma unidade de pensamento. Para esses, não existe a constituição de uma Ciência sem Filosofia e sem uma série de ideias trans científicas (BARBOSA, 2013).

Quando falamos de Ciência no contexto europeu do século XVIII, tema da primeira seção desse texto, nos referimos ao modo de compreender, descrever e explicar o funcionamento do mundo físico adotado pelos intelectuais da época, tanto no sentido da racionalidade científica quanto da reflexão filosófica. Buscamos a influência que filósofos e cientistas europeus exerceram no pensamento de Luís António Verney e o levaram a elaborar um verdadeiro método de estudar para Portugal. 
Fizemos um recorte para o estudo e assumimos como parâmetro os pensamentos do inglês Francis Bacon, empirista que defende o método indutivo como a verdadeira interpretação da natureza, portanto crítico do método dedutivo e do silogismo; também nos referendamos no francês René Descartes, considerado pai do racionalismo, que defende o ceticismo metodológico e com ele o método cartesiano, dedutivo; por fim, o pensar do filósofo Isaac Newton, naturalista e um influente cientista da Europa, responsável pela produção e descobertas de leis aplicadas à Física.

Na segunda seção, abordamos Portugal em um contexto de Modernidade. Tratamos da decisão da Coroa Portuguesa de abrir suas portas ao Iluminismo Europeu sem abnegar da relação religiosa com a Igreja Católica como garantia de preservação da monarquia divinamente instituída. Nesse contexto, concordamos com a existência de uma vertente específica do Iluminismo, chamando de Iluminismo Moderado ou Iluminismo Católico.

Por fim, como centro da análise desse estudo, temos o católico oratoriano Luís António Verney e sua obra $\mathrm{O}$ Verdadeiro Método de Estudar, para ser útil à República e à Igreja: proporcionado ao estilo e a necessidade de Portugal. A publicação aconteceu em dois tomos, 1746 e 1750, respectivamente, e apresenta o pensamento iluminista português. As concepções de Ciência na obra verneyniana foram analisadas a partir do contexto socio histórico português. Para a análise, inicialmente, focamos o título da obra e as possibilidades de critérios utilizados por Verney para sua escolha; e por fim, a carta de Física por apresentar um diálogo com vários pensadores da época e se constituir a principal parte da Filosofia que interlaça o corpo e o espírito, segundo o próprio Verney.

Entendemos que o movimento de compreensão dos aspectos internos da obra e de sua relação como o contexto socioeconômico de criação permite conhecer um pouco da concepção verneyniana de Ciência e traçar o desenho de educação no referido período em Portugal. De forma que, não assumimos a pretensão de construção do conceito de Ciência e nos reservamos de tendências anacrónicas quando tratamos de compreender a educação e seu método de ensinar e aprender. Ao tempo que almejamos como objetivo para esse texto traçar algumas considerações acerca da Ciência na obra de Verney dado a profundidade de sua escrita e das propostas apresentadas.

\section{A Ciência no contexto europeu do século XVIII}

O século XVIII ficou marcado pela crítica à filosofia escolástica, a supremacia da razão e a busca da verdade onde o homem ganha a centralidade. Do ponto de vista filosófico, essa 
corrente é chamada de Racionalismo e se estruturou a partir de mudanças basilares no pensamento dos intelectuais europeus. O homem passou a ser concebido como sujeito do conhecimento, capaz de construir os objetos de conhecimento a partir das próprias representações mentais. Assim, a realidade passou a ser um sistema de causalidade e poderia ser conhecida e transformada pela racionalidade do homem.

Os Racionalistas entendiam que a Razão é inata aos homens e se constitui fonte do conhecimento. O raciocínio lógico se estruturou pela dedução de ideias. A Matemática se encarregou de representar a natureza como um conjunto de leis que obedecem a uma regularidade. Assim, para conhecer a realidade, composta da natureza e seus fenômenos, o homem passou a utilizar mecanismos mentais físico-matemáticos de onde originou a Ciência.

Um dos pensadores racionalistas nesse período foi René Descartes (1596-1650). Filósofo e cientista francês, Descartes entendia que a realidade existe independente do homem, portanto se constitui objeto de conhecimento. Para ele, a verdade é o resultado da relação entre as coisas que existem no mundo real e o pensamento do homem. A Filosofia de Descartes se fundamenta na dúvida. A dúvida passa a ser entendida como uma forma sistemática de se chegar à verdade. Com a descoberta de Galileu Galilei (1564-1642), onde por meio de um instrumento foi possível flagrar o espaço cósmico e revelar que a terra gira em torno do sol, e não o contrário como a percepção humana indicava, a desconfiança de Descartes acerca da fragilidade dos critérios sensoriais do homem se confirma.

A Ciência, quando guiada por um método definido, revelaria os segredos da natureza e produziria conhecimento verdadeiro e confiável ao homem. Em O Discurso sobre o Método, sua principal obra, Descartes (1996) expressou seu desapontamento e desencontro com a Ciência praticada nas universidades europeias guiada pelos parâmetros aristotélicos e decidiu buscar o conhecimento dentro de si mesmo ou na natureza. Empreendeu a busca de uma verdade irrefutável que servisse como princípio elementar do conhecimento e assumiu o caráter dedutivo em seu método de fazer Ciência. Para o filósofo, o método matemático, racionalista era a forma segura de se chegar ao conhecimento. Surgiu o método cartesiano.

Outra corrente filosófica do século XVIII defendeu que a Ciência deveria guiar-se pelo método científico empírico. O conhecimento científico se constituiria verdade se passasse pela comprovação e pela experiência sensorial. Com a centralidade da experiência na busca do saber científico passou-se a adotar uma metodologia rigorosa onde as hipóteses e teorias deveriam ser testadas, em contrapartida, as afirmações metafísicas deveriam ser rejeitadas devido à ausência de experimentação. 
Um dos intelectuais que adotou essa postura filosófica foi Francis Bacon (1561-1626), filósofo, político inglês e crítico da filosofia escolástica. Para Bacon, a filosofia escolástica era essencialista e sem experimentação, portanto sem efeitos práticos para a vida do homem. $\mathrm{O}$ conhecimento deveria conduzir à verdade, por isso ser experimental, empírico. Logo, o verdadeiro cientista, como filósofo da natureza, deveria utilizar o método indutivo como caminho ideal para a investigação. Nele, se parte da observação dos fatos e do empirismo para se chegar as conclusões.

Bacon (2003) entendeu que o conhecimento deveria ser medido pelos seus resultados e funcionalidades para o homem. Para cumprir essa função, o conhecimento deveria estar fundamentado em fatos, apreciados via observação e experimentação. A verdade, para o pensador, somente seria possível mediante a observação passiva e objetiva dos fenômenos da natureza para se alcançar as leis (universais) que os explicam. Vale ressaltar que o filósofo buscou não conjecturar e nem testar os fenômenos da natureza, mas desvelar a realidade com explicações objetivas advindas de observações neutras.

Ao analisarmos a Ciência no contexto europeu do século XVIII a partir de dois dos seus intelectuais, um francês e o outro inglês, parece notório os caminhos diferentes que ela começou a apontar, que convergem, mas nunca se tornaram uno. Enquanto Descartes assume uma postura filosófica racionalista e adota o método dedutivo como o caminho seguro para a busca do conhecimento, o empirista Bacon reconhece o método indutivo como o mais apropriado e aponta a importância da experiência na Ciência da Natureza. Assim, a Ciência no contexto europeu se apresenta como uma busca da verdade através da razão com duas possibilidades metodológicas: o método dedutivo e o método indutivo.

Esse contexto da história intelectual ficou conhecido como o século das Luzes ou Iluminismo. No que diz respeito a Filosofia Natural, parte do grupo dos iluministas tomou a obra de Isaac Newton (1643-1727) como um arranjo harmônico das vertentes filosóficas seguidas pelos intelectuais que o precederam. O newtonianismo, enquanto fenômeno da história intelectual, pode ser tomado como peça importante da Ciência Iluminista; um fenômeno decorrente da compreensão e divulgação do método experimental e das leis gerais da natureza formulada por Newton para além dos círculos das Ciências, Física e Matemática.

Isaac Newton foi sistematizador da obra de Descartes, de Bacon e outros; desenvolveu uma formulação matemática de concepção mecanicista da natureza; estabeleceu o paradigma mecanicista ou newtoniano-cartesiano. No que trata de método científico, conseguiu agregar o método empírico-indutivo e o racionalista-analítico-dedutivo. Ultrapassou Francis Bacon em 
sua experimentação sistemática e René Descartes em sua análise matemática. Unificou as duas tendências.

Nesse sentido, Oliveira (2011) entende o newtonianismo como um fenômeno intelectual que representou para a Filosofia iluminista um paradigma do conhecimento global incorporado nos mais variados horizontes de investigação, extrapolando a temática da Física e alcançando outros nichos do conhecimento, inclusive estendendo-se à Ciência do homem. A física de Newton foi capaz de explicar mais do que o movimento da terra, sua explicação assumiu cunho materialista, de experiência e de observação. O intenso uso de instrumento matemático possibilitou o surgimento de um novo método de praticar a Filosofia Natural.

Para compreender o método de Newton podemos elucidar diferentes pontos de sua cadeia conceitual, como o estudo das causas físicas, dos princípios metafísicos e do entendimento da matematização da natureza. Segundo Oliveira (2011), Newton defende a doutrina da externalidade do movimento da matéria, ou seja, a regularidade e a coerência do universo eram provas de uma ação atribuída a um Ser inteligente e poderoso, Deus. Pertencente a tradição físico-teológica, Newton defendeu a relação de dependência da mente e do movimento a um Ente externo e superior.

A relação Deus-Natureza nos remete ao conceito de Teologia Natural tratado por Ferreira (2016) que constitui a atribuição de uma função religiosa à natureza como propuseram Descartes, Newton e Locke. Para o autor, o Iluminismo praticado em Portugal, o Iluminismo Católico, efetivado pela reforma pombalina e pensada por intelectuais como Ribeiro Sanches (1699-1782) e António Verney (1713 -1792) seguiam a mesma linha teológica que procuraram harmonizar os avanços da Ciência com a autoridade da Bíblia Sagrada.

De fato, Portugal não esteve alheio ao contexto Iluminista da Europa e suas efervescentes correntes científicas, muito menos às influências de Isaac Newton. Durante o reinado de D. João V (1706-1750), o país começou a abrir as portas para que a centelha de Luz penetrasse com sua face mais moderada. A aceitação da existência atuante de Deus era presente nessa vertente do Iluminismo e nas concepções de Ciência que surgiram. Para intelectuais como Descartes, Deus era a causa primeira de tudo; para Newton e outros da mesma linha, Deus era a causa primeira e atuante no mundo natural. Logo, seria contrário a Razão acreditar que toda harmonia existente no universo foi obra do acaso.

Entretanto, assumir a teologia natural não significa, necessariamente, aceitar o pensamento escolástico considerado não explicativo e dogmático. Significa o deslocamento do lugar de Deus nas concepções emergentes de Ciência. Assim, as instituições religiosas nos séculos XVI a XVIII viveram dificuldade para se legitimarem frente às descobertas científicas. 


\section{Portugal em um contexto de Modernidade}

As ideias iluministas chegaram à Portugal inseridas em um quadro geral de transformações que marcaram a sociedade europeia no século XVIII. Aspirou-se adotar as ideias modernas derivadas da Revolução Científica ao mesmo tempo em que se corroborava a existência do Poder Real como monarca de direito divino, portanto sem abrir mão das doutrinas da Igreja Católica. Nessa conjuntura contextual, as linhas mais radicais do pensamento iluminado foram fortemente combatidas. A vertente moderada do Iluminismo buscou, segundo Ferreira (2016), uma conciliação entre as teses de intelectuais modernos e as doutrinas do catolicismo. A polaridade, Ciência e Teologia, marca o pensamento de iluminados de países católicos e suas colônias sem poupar críticas à Escolástica e à Companhia de Jesus.

De fato, a Revolução Científica levantou uma questão central com a qual a Igreja precisou lidar: o conhecimento para ser validado precisava de observação e experimentação. Somada a essa questão, a Igreja não pôde desperceber a presença crescente de iluminados que rejeitavam qualquer tipo de intervenção divina na natureza (ateísmo) e daqueles que acreditavam ter sido o mundo criado de uma vez e desde lá passou a ser gerido por leis fixas e invariáveis (deísmo). A última postura filosófica tanto defendeu quanto atacou o cristianismo católico, sendo os seguidores da ordem da Companhia de Jesus, ou jesuítas, o principal alvo.

Silva (2013) aborda o movimento antijesuítico e apresenta variados motivos para o projeto de expulsão dos jesuítas, marca do período pombalino. Para ele, a própria estrutura hierárquica da ordem da Companhia de Jesus desafiou a Coroa por reafirmar obediência à Roma como prioritária às autoridades régias; outro imperativo foi seu sólido poder econômico erguido no centro do império português que representava uma ameaça ao poder dos monarcas. Afinal, além dos vastos privilégios concedidos pela Santa Fé e reconhecidos pelos reis portugueses aos principais campos de atuação dos jesuítas, o missionário e o pedagógico, a Companhia de Jesus tornou-se uma das instituições mais opulentas da América Portuguesa.

Outra crítica aos jesuítas vinha de intelectuais portugueses, por vezes nas pessoas dos estrangeirados, que os responsabilizavam pela decadência cultural e científica dos portugueses em relação as revoluções que marcavam o campo científico na Europa. Assim, os limites de atuação exercida pelos jesuítas, especialmente no campo educacional, começaram a serem impostos mesmo antes de D João V (1689-1750) ascender ao trono e tutelar o Marquês de Pombal (1699-1782) em Portugal. A aproximação da realeza portuguesa com a Ordem dos Oratorianos parecia indicar o desejo de permitir inovações na administração do Estado e 
aproximação de Dom João V com os iluminados. Além do que, os oratorianos, ao contrário dos jesuítas, reconheciam e se submetiam ao poder da Coroa.

Antes de continuarmos a comparação entre as ordens religiosas, Companhia de Jesus e a Congregação do Oratório, façamos uma retrospectiva da chegada dos oratorianos à Portugal.

Desde 1668, após a Confraria de Nossa Senhora das Saudades, Bartolomeu de Quental (1627-1698), pregador e capelão da família real desde D. João IV (1640-1656), apresentou para Portugal a Congregação do Oratório de Nossa Senhora de Assunção de inspiração italiana e fundada por Felipe de Néri (1515-1595), contemporâneo de Inácio de Loyola (1491-1556). O termo oratório se refere ao lugar destinado ao culto católico, mas sem a designação de um espaço sagrado. Logo, terem os oratórios funções religiosas diferentes das Igrejas não requeriam afiliação dos participantes, pagamentos de anuidades e nem ajuda financeira para as missas, sepultamentos e outros ofícios prestados pela irmandade. A Congregação do Oratório se inspirou na tradição desses oratórios e assumiu uma religiosidade voltada à comunidade de habitantes miseráveis e doentes. Segundo Silva (2013), essa forma de atividade religiosa com ênfase na caridade desenhou um modelo de religiosidade que encontrou espaço no contexto oitocentista.

Contudo, as Congregações do Oratório fundadas em Portugal assumiram características singulares e ao gosto da realeza portuguesa, de modo que não apresentavam grandes semelhanças com o modelo estabelecido por Felipe Néri, na Itália, e nem por Pierre Bérulle, na França. Os oratorianos em Portugal conservaram apenas alguns pontos de contato com seus irmãos italianos e franceses. Dos italianos, conservavam o exercício da caridade, a prática da oração, a acolhida de leigos vinculados à congregação, as restrições às mortificações, o caráter urbano da congregação e a liberdade que norteava a entrada e a saída na irmandade. Dos franceses derivaram a inspiração do programa curricular de ensino dos colégios e do modelo centralizado de administração.

Conforme Silva (2013), para ser admitido como oratoriano o jovem deveria apresentar pureza de sangue; boas condições de saúde; idade entre 18 e 45 anos; conhecimento do latim e outra língua. Todos os seus membros eram eleitos a cada três anos e compunham uma estrutura hierarquizada: o preprósito geral (prelado), prefeito, procurador e três deputados responsáveis por eleger os demais cargos da congregação. Os gastos eram custeados pelo patrimônio próprio, doações dos fiéis e privilégios reais.

No que trata da ação educativa dos oratorianos, no início estava mais voltada ao ensino católico e às práticas religiosas que conduziriam à pureza e à perfeição humana e menos às ações pedagógicas de natureza científica. Entretanto, a situação logo se inverteu. Com o apoio 
da Coroa portuguesa e da aristocracia, a Congregação do Oratório começou a focar a atividade pedagógica e em pouco tempo se configurou como alternativa aos colégios jesuítas com novas diretrizes pedagógicas e filosóficas.

Esse novo campo de atividade da congregação tomou forma ao ponto de estar estruturado para sustentar um projeto político-institucional em oposição a escolástica, a partir da tutela joanina, durante a primeira metade do século XVIII. Nesse período, os colégios oratorianos representavam concorrência significativa ao jesuíticos e os estudantes tinham a possibilidade de ingressar na Universidade de Coimbra, prerrogativa dada anteriormente apenas aos jesuítas.

Silva (2013) nos informa que, apesar dos oratorianos nunca conseguirem equiparar sua obra àquela realizada pela Companhia de Jesus, eles demonstraram que a intelectualidade portuguesa não dependia dos jesuítas. Denunciaram sua desgastada escolástica e peripatetismo, bem como a fragilidade de suas bases teóricas no plano da Filosofia, Lógica, Retórica, Gramática e Pedagogia. Diante das graças da Coroa e da sociedade portuguesa, receberam como doação a Casa de Nossa Senhora das Necessidades, em 1745, e uma grande biblioteca onde ensinavam Teologia, Moral, Filosofia, Retórica e Gramática Latina aos jovens portugueses.

Devido ao apego à religiosidade ou à teologia por parte dos oratorianos, alguns estudiosos, como Ferreira (2016), veem com cautela a suposta adesão dos oratorianos aos novos parâmetros da Ciência Moderna que tendia a explicação racional da natureza e a secularização do conhecimento científico, uma característica da modernidade. Como um exemplo claro deste dualismo entre o antigo e o novo modelo de Ciência presente no pensamento intelectual de iluminados, analisaremos o oratoriano Luís Antônio Verney.

\section{Luís Antônio Verney e o Verdadeiro Método de Estudar}

Luis António Verney nasceu em 1713, em Lisboa, e morreu em 1792, em Roma, portanto foi testemunha das principais mudanças que eclodiram com força durante o século XVIII na Europa. No seu processo de formação estudou de gramática à retórica em colégios jesuítas. Fez mestrado em Artes pela Universidade de Évora e doutorado em Teologia e Direito pela Universidade de Roma.

Era considerado um estrangeirado português, um conceito, a priori, relacionado aos homens adeptos do pensamento iluminista, o que havia de mais moderno no período. No entanto, o termo também sustentava certo nível de preconceito por parte da tradicional sociedade portuguesa que via a postura filosófica moderna como ameaça a ordem instituída. 
Assim, apesar de ser tratado com certas reservas por parte da nobreza, Verney gozou de certos privilégios como intelectual ilustrado na corte portuguesa e entre os representantes portugueses na Itália, principalmente devido ao seu vínculo com a Congregação do Oratório.

Embora alguns autores admitam António Verney como oratoriano (SILVA, 2013; RUCKSTADTER, 2012; OLIVEIRA, 2011) há aqueles, como Ferreira (2016), que apontam para o fato de não existirem provas da sua afiliação à Congregação do Oratório. Para este, António Verney era simpatizante dos oratorianos devido ao contato com um irmão, Diogo Verney que fazia parte da Congregação. Neste estudo, apresentamos Luis António Verney como oratoriano, corroborando o pensamento da maioria dos estudiosos do estrangeirado e por entendermos que a temática extrapola o bojo do delimitado para o momento.

Sua principal obra, O Verdadeiro Método de Estudar: para ser útil à República, e a Igreja (1746), está organizada em dois tomos, compostos por oito cartas cada um ${ }^{1}$. A obra se configurou como uma ferrenha crítica a ordem católica conhecida e apoiadora da Igreja desde a época da Reforma, a Companhia de Jesus, dirigida por um seguidor do Iluminismo, também católico. Para De Andrade (1980), a polêmica em torno da obra verneyniana teve início durante a solicitação de licença para sua divulgação ao Tribunal da Santa Inquisição. Os mais de dez inquisidores, após lerem e relerem suas páginas, decidiram apreender e proibir sua circulação, todavia a decisão parece não ter sido unânime uma vez que ela foi lançada de maneira clandestina por um dos inquisidores que era favorável as ideias expostas.

Em um estudo acerca da obra O Verdadeiro Método de Estudar, Ruckstadter (2012) indica que as concepções de Verney marcam também a escolha do título da sua obra. Os termos 'verdadeiro' e 'método' nos fazem lembrar as características que a Ciência assume a partir da Modernidade. A Ciência no século XVII se estruturou em critérios racionais para desvendar a verdade. René Descartes e Francis Bacon, como vimos anteriormente, foram duas matrizes importantes nesse modelo de pensamento moderno. A verdade passou a ser um critério para convencer a opinião pública em Portugal e, consequentemente, o poder político.

Para tornar hegemônica sua teoria, os intelectuais empreendiam esforços para convencer o maior número possível de pessoas esclarecidas da veracidade das suas descobertas e da superioridade de sua Ciência. Para Chauí (1998), formar a opinião pública era um embate ideológico no período. Caberiam aos filósofos iluministas divulgar suas ideias e torná-las aplicáveis para universalizar a particularidade do seu método.

\footnotetext{
${ }^{1}$ Carta I - Gramática e ortografia da língua portuguesa; Carta II - Gramática Latina; Carta III - Latinidade; Carta IV - Grego e hebraico; Carta V - Retórica; Carta VI - Continua o estudo da Retórica; Carta VII - Poética; Carta VIII - Filosofia; Lógica; Carta IX - Metafísica; Carta X - Física; Carta XI - Ética; Carta XII - Medicina; Carta XIII - Jurisprudência; Carta XIV - Teologia; Carta XV - Direito Canônico; Carta XVI - Observações várias.
} 
Portanto, de acordo com Ruckstadter (2012), um 'verdadeiro método' representaria um caminho seguro para todos aqueles que investigam algum fenômeno natural para desvendá-lo aos olhos da sociedade moderna. O método moderno nasceu no âmbito das Ciências Naturais, pois se entendia que ao desvendar os segredos da natureza poderia desvendar os segredos do próprio homem. Vale ressaltar que Verney não apresenta um método verdadeiramente novo no sentido de patentear sua criação, mas seu mérito encontra-se exatamente na capacidade de dialogar com as diversas concepções emergentes na Europa e se apegar ao que julgava como verdadeiro nos métodos e concepções de Descartes, Bacon e Newton. Assim, o verdadeiro método era composto por diferentes contribuições dos intelectuais iluminados.

Para Ruckstadter (2012), o termo seguinte, estudar, se constitui núcleo verbal da sentença, o verdadeiro método de estudar. Chama à atenção o fato de Verney deslocar o foco do 'ensinar' para o 'estudar' nas questões que envolvem a educação e a prática pedagógica em Portugal. De fato, a educação formal, como enfoque voltado para o estudo, adquiriu um novo significado na Europa Oitocentista e se tornou o valor diferencial entre os indivíduos na sociedade portuguesa. Ademais, o destaque nas tendências filosóficas da época era o método de estudo seguido pelo cientista. As metodologias de base aristotélica e escolásticas já não se sustentavam. Desse modo, tornou-se necessário novos método de investigar a natureza.

Treinar corretamente o estudante da educação formal para se tornar um cientista envolvia, acima de tudo, ensina-lo a estudar a partir de uma metodologia correta que possibilitasse a descoberta da verdade. Só assim, a mocidade portuguesa se tornaria 'útil' à República e à Igreja. Esse entendimento nos leva, segundo Ruckstadter (2012), à segunda sentença do nome atribuído por Verney à sua obra: para ser útil à República e à Igreja.

O pensamento de Verney estava alinhado a tendência dos iluministas que concentravam suas reflexões em propostas que pudessem ter aplicações práticas. Nas cartas da obra, o autor insiste em refutar toda a educação que estivesse desvinculada com a realidade prática. Nesse sentido, julgava que o ensino jesuítico era descabido para o período vivenciado por negligenciar um modelo de educação e de uma cultura útil à República.

Ao fazer alusão aos termos República e Igreja ao gosto da teologia natural, para Ruckstadter (2012), indica que Verney de um lado, se preocupava com um método de estudo que fosse útil para o bem público, que servisse para a formação do homem e para a vida em sociedade regida por leis que assegurassem o bem comum. De outro lado, o termo Igreja associado à República indicava a posição política e filosófica de Verney ligada à sua formação católica e às características do movimento das Luzes em Portugal. 
Entretanto, ser útil à Igreja, para Verney, parece não representar uma defesa de um ensino voltado à formação de religiosos, mas uma tentativa de conciliar Ciência e fé no programa de ensino proposto para Portugal com vista à formar bons cristãos, qualquer que fosse a profissão exercida na sociedade. Ao acrescentar no subtítulo da obra o termo 'ao estilo e necessidade de Portugal', Verney expõe o propósito central de seu programa de reformas do ensino: reformar a mentalidade portuguesa sem violar sua singularidade.

Ainda, Ruckstadter (2012) acredita que ter sido a obra verneyniana escrita no anonimato contribuiu para a sua circulação, pois criou um movimento entre os leitores para identificar o suposto padre franciscano, R. P. ***2 Barbadinho da Congregação de Itália que assina a carta e a direciona ao R. P.***Doutor da Universidade de Coimbra. Para instigar mais curiosidades, sua segunda edição, lançada no mesmo ano, traz como referência a editoração feita na oficina de António Balle, em Valença.

O conteúdo do livro não instiga menos curiosidade, pois ele apresenta uma proposta de reforma em Portugal através da Educação e de um Método de Estudar, adjetivado como verdadeiro, além de assegurar sua utilidade à República e à Igreja. Logo, se tornou o centro de uma disputa dos preceitos religiosos, políticos e pedagógicos entre oratorianos e jesuítas. Tal disputa, particularmente em Portugal, retrata o enfrentamento de duas visões de mundo e concepções de educação que emergem em uma sociedade que se deseja moderna, racional e que busca uma verdade científica através de um método de investigação sem abdicar do poder da Igreja nas decisões políticas e na formação de sua mocidade.

Ademais, Ruckstadter (2012) nos adverte que, latente a oposição de projetos pedagógicos entre jesuítas e oratorianos estava a luta pelo domínio pela via de formação no modo de pensar a sociedade, a economia e a cultura oitocentista, somado do almejo pelo prestígio político junto à Coroa. Assim, no entendimento da autora, os jesuítas não estavam tão alheios às principais revoluções científicas modernas, conforme apregoava a movimento antijuítico, nem os oratorianos tão iluminados quanto se apresentavam.

É fato, segundo Ruckstadter (2012), que a Companhia de Jesus foi desde sempre uma ordem religiosa polêmica. Apesar de atrair simpatizantes, convivia com a repulsa de muitas pessoas, mesmo dentro da Igreja Católica, como é o caso da Congregação dos Oratórios, grande responsável pela formação e divulgação da imagem negativa dos jesuítas em Portugal. Os principais ataques não pouparam áreas da Companhia, atingiram a teologia e a eclesiologia

${ }^{2}$ Marcas (***) presentes na obra de Verney. 
jesuítica, os preceitos políticos e moral que a sustentavam, a pedagogia desenvolvida nos seus colégios e, principalmente, o seu método julgado como retrógado e inútil.

Nos dois últimos campos, o pedagógico e o método científico, os oratorianos propunham a implementação das Ciências Naturais em Portugal a partir do pensamento de Francis Bacon, Descartes e Newton, dentre outros. Defendiam o ensino da língua, da gramática e da ortografia portuguesa independente do latim. Para o autor do Verdadeiro Método de Estudar o método aplicado pelos jesuítas conduzia o estudante a um saber apenas contemplativo, sem utilidade em uma sociedade moderna do século XVIII. Assim, Verney propunha um novo método para estudar, o verdadeiro, assumido pela Ciência Moderna, portanto parametrizado pela razão e pela experiência.

Um enfoque na estrutura interna da obra, composta por cartas, torna possível perceber que elas seguem um esquema geral comum. Na introdução, o autor conceitua a área, em seguida ressalta a sua importância e, finalmente, dá informações do seu histórico e ajustes de melhoria. Embora enalteça a antiguidade clássica, acautela quanto aos seus ensinos, fato condizente com seu propósito inovador de romper com o predomínio da autoridade. Assim, Verney reconheceu a importância dos estudos realizados por Galileu Galilei (1564-1642), René Descartes (15961650), Francis Bacon (1561-1626) e Isaac Newton (1642-1727) para a Filosofia Moderna. Dialogou com cada cientista da época e se fundamentou no que entendeu como o melhor em cada um deles para contrapor o conhecimento de base jesuíta.

A análise da dedicatória de $\mathrm{O}$ Verdadeiro Método de Estudar permite perceber a sutileza com que Verney começou o debate sobre a construção de uma concepção iluminista da Ciência e da educação, bem como de um posicionamento declarado alinhado ao movimento antijesuítico. Apesar de não ser oficialmente o pensador das reformas pombalinas, sua obra contribuiu para o debate sobre os métodos de ensino e a organização dos estudos em Portugal. As propostas apresentadas por Verney configuram a adoção de novos paradigmas de ensino norteados por novas direções da Ciência e Método Científico.

Verney critica o período medieval que, para ele enquanto iluminista, representava séculos de sombras em relação ao conhecimento, principalmente no que tange a Física. Em sua carta dedicada aos estudos da Física, considerada por ele parte importante da Filosofia, Verney apresenta a polaridade antigo versus moderno e posiciona-se ao lado dos argumentos dos modernos, especialmente em sua crítica aos peripatéticos (MENDES, 2006)

Para Verney, a Física é "a parte principal da Filosofia” (VERNEY, 1950, v.2, p. 168). Afinal, Física é "a Ciência que examina a natureza do Corpo e Espírito mediante os efeitos que conhecemos" (VERNEY, 1950, v.2, p 207). De forma que, primeiro 
é necessário formar verdadeira ideia do corpo, e, pondo de parte todos os prejuízos, examinar qual é a natureza daquilo a que todos constantemente chamam de corpo. (VERNEY, 1950, v.2, p. 207-208).

A partir daí a Física se estrutura sobre as bases da Matemática, da Geometria e do Cálculo

mostra o Físico as leis do movimento dos corpos, a acção mútua dos corpos duros e elásticos e compreende os movimentos da gravidade. Tanto absoluta como equilibrada, a que chamamos Mecânica ou Estática, etc. Com ela explica as leis dos corpos fluidos, a que se chama Hidrostática e Hidráulica, segundo as coisas que considera (VERNEY, 1950, v.2, 209-210).

Em seguida, na visão de Verney, a Física se encarrega do espírito

Tendo examinado a natureza dos Corpos, deve examinar a dos Espíritos. Deve, pois, o estudante, seguindo o mesmo método, provar a existência e a espiritualidade da nossa alma (VERNEY, v.2,1950, p. 238).

Por fim, a Física chega ao objetivo: examinar a natureza usando as faculdades de pensamento, da razão

Finalmente, deve o Filósofo examinar a existência do espírito incriado, o princípio de todas as coisas. Este deve ser o principal empenho do Filósofo pois este é o fundamento de toda Filosofia e Religião e tudo que se examina com a luz da boa Razão (VERNEY, 1950, v.2, p. 244)

Ou seja, Verney entende que a Física deve tratar da relação do corpo com o seu criador, Deus. Essa atividade é tão importante para a Física que se tornou o fundamento de "toda a filosofia e religião"(VERNEY, 1950, v.2, p. 244). Nesse ponto, as concepções verneyniana se ligam diretamente a Locke (1983, p. 343) para quem a Física deveria incluir "a matéria e corpo, mais o espírito também, que tem sua própria natureza, constituições e operações, assim como o corpo"

$\mathrm{Na}$ carta da física, Verney demonstra a incompatibilidade entre o método moderno e o aristotélico. Portanto, se o ensino de Física se quisesse moderno deveria romper formalmente com a escolástica ou com o aristotelismo.

Nem vale o dizerem que alguns mais modernos recebem as experiências. Isto são arengas; porque, neste particular, não há meio. Quem recebe as experiências, e, em virtude delas, quer discorrer, deve renunciar ao Peripato; quem abraça o Peripato deve renunciar as experiências. São coisas totalmente opostas, que uma destrói a outra (VERNEY, 1950, v.2, p. 278)

Ferreira (2009) entende que Verney se referiu aos autores que, na época, ainda mantinham vínculo com Aristóteles, dentre eles Azevêdo Fontes e o Padre João Batista. Entretanto, o estudioso da obra acautela que essa referência não pode ser entendida como aversão aos pensamentos aristotélicos. No contexto apresentado, Verney parece evidenciar que o problema do peripato reside no fato de estar defasado em relação ao século XVIII. Adepto do 
uso da experiência como forma de comprovação da verdade, o iluminista se mantém alinhado ao pensamento empirista e newtoniano.

De outro lado, nem todos os autores considerados modernos, de fato o são na visão de Verney. A esses "meio modernos" ele elenca com ressalvas.

Devo admitir a V. P. que há grande diversidade entre uns e outros Modernos. Os primeiros que sacudiram o jogo de Aristóteles, como Catésio [Descartes] e Gasendo, ainda que fossem Anti-Aristotélico nos fundamentos, muitos se inclinavam ao Peripato no método. [...] Por isso, Cartesianos e Gasendistas, ainda que se chamem moderno porque se fundam em experiência, contudo são Filósofos hipotéticos porque si põem a muitas coisa que não provam (VERNEY, 1950, p. 199-201).

É perceptível a preferência pelo modernismo inaugurado por Isaac Newton (1643-1727) que desprezou as hipóteses. O método defendido por Verney é o praticado pelas academias científicas da Europa, dentre elas "Londres, Paris, Leopoldina, Berlim, Bolonha e São Petersburgo" (VERNEY, 1950, p.201). O processo racional do método verdadeiro para estudar Física se evidencia em seguida.

Este é o sistema moderno: não ter sistemas; e só assim é que se tem descoberto alguma verdade. Livre da paixão, cada Filósofo propõe as suas razões sobre as coisa que observa; as que são claras e certas, abraçam-se; as duvidosas, ou se rejeitam, ou se recebem no grau de conjecturas, enquanto não aparecem outras melhores; e assim é que se forma o corpo da doutrina. (VERNEY, 1950, v.2, p. 220-203)

A matematização é um dos aspectos metodológicos fundantes do pensamento de Galileu Galilei (1564-1642). Além disso, o cientista defendeu a observação e a experimentação na construção do conhecimento, consideradas requisitos para a construção da própria Ciência. Essa construção se daria a partir de conceitos matemáticos, por isso Verney defende que não é possível ser um bom Filósofo sem conhecer a Matemática e destaca que os principais nomes da Filosofia Moderna eram também renomados matemáticos

Para Verney o cartesianismo era mais engenhoso que verdadeiro. Ao afirmar que o verdadeiro sistema moderno não tem sistema, não recusa o método ou o uso da razão, mas a existência de um sistema de hipóteses fundamentais (FERREIRA, 2009). Para ele, o racionalismo de Descartes, por admitir tais hipóteses fundamentais, era uma espécie de nova escolástica.

A Álgebra, que é uma Aritmética literal, mediante a qual se facilitam as demonstrações e se descobrem muitas coisas que antigamente se ignoravam e algumas não se sabiam provar. Com estas preparações é que o Físico poderá mostrar as leis e propriedades do movimento, sem o conhecimento das quais não se pode dar um passo na Física (VERNEY, 1950, v.2, p. 209).

No fragmento, Verney parece trazer a ideia de leis do movimento e colocar em evidência o que havia de central na Filosofia moderna: que os resultados da experiência e da observação 
podem ser demonstrados matematicamente permitindo que se prove as descobertas. Assim, Verney trouxe à baila o tripé do modernismo em sua face newtoniana: experiência, observação e prova. Outro ponto de encontro entre as concepções de Verney e a Física newtoniana, segundo Ferreira (2009), é o fato de atribuir à Geometria e a Álgebra a descoberta de coisas até então ignoradas.

\begin{abstract}
entendem os Peripatéticos que a Astronomia é verdadeira Matemática. A Astronomia, porém, nada mais faz que explicar os fenômenos dos Céus que nós vemos, digo os movimentos dos Planetas; e, como não pode explicar isto sem saber as propriedades dos triângulos e linha curvas, porque estes é que ensinam a não errar nos raciocínios, daí vem que lhe chamam Matemática. Mas esta razão milita na Física. Expliquem-se V. P. a aceleração do movimento de uma grave que cai perpendicularmente, ou por um plano inclinado, ou que penetra em um fluido, ou qualquer outro fenômeno natural; não poderá dar perfeita razão disto sem os princípios da Matemática, motivo também pelo que digo que a Física discursiva é Matemática Mista. Nela, a experiência reputa-se por dado, e o raciocínio é deduzido da matemática que ensina a não errar nos discursos. (VERNEY, 1950, v.2, p.213).
\end{abstract}

Verney critica o fato de os jesuítas chamarem de Matemática assuntos que pertencem ao campo da Física. A partir do fragmento acima, Verney explica que a Astronomia se propõe evidenciar os movimentos dos planetas, movimento que são observados por homens, ao passo que a Matemática é usada para explicar os movimentos. No entanto, utilizar Matemática para explicar a Astronomia com a linguagem matemática não faz a Astronomia uma Matemática.

Oliveira (2011) explica que a Matemática para Verney é dividida em matemática simples e matemática mista. A primeira é composta de Geometria e Aritmética e a segunda envolve a Mecânica, Estática, Hidrostática, Astronomia, Óptica e Geografia que pertencem a Física e devem ser examinadas pela procedimentos matemáticos.

No entendimento do autor, a obra o Verdadeiro Método de Estudar elabora uma explicação do newtonianismo e lamenta a separação entre Matemática e Física, pois a primeira tem a capacidade de explicar as descobertas realizadas pela segunda. Reconhece uma linguagem consensual, entende o quanto o desenvolvimento da Matemática está atrelada a Astronomia, mas, no momento de apresentar isso, aponta apenas as vantagens da Matemática enquanto um instrumento da linguagem para a Filosofia Natural.

\title{
Considerações finais
}

O Verdadeiro Método de Estudar tem como ponto central a proposta de uma renovação do pensamento científico e teológico em Portugal. A Ciência, para Luís António Verney deve seguir os critérios iluministas em um contexto de modernidade: observação, experiência e prova. Entretanto, o estrangeirado não enxerga dualidade entre a Ciência e a Teologia, seguindo 
o mesmo pensamento de Newton e Descartes. Nesse sentido, parece que as descobertas de Isaac Newton e a teoria newtoniana encontram centralidade da discussão de Verney.

Como oratoriano, o autor de O Verdadeiro Método de Estudar se opôs à filosofia jesuítica desde a sua essência, passando pelas suas crenças até chegar ao seu modelo pedagógico. Como ex-estudante de colégio jesuítico, Verney pôde falar com propriedade da dinâmica das aulas nos colégios e de como era organizado o estudo a partir das ideias aristotélicas.

Embora em algumas passagens de sua obra, o autor reconheça a importância dos clássicos da antiguidade entende que o conhecimento deve assumir como critério a utilidade para a vida em sociedade, portanto a educação e o estudo só encontram o sentido pleno quando passam pelo critério de utilidade. Nesse sentido, postula a inutilidade das discussões escolásticas para o que deveria ser o verdadeiro papel do cristão naquele momento: defender a religião católica perante as vertentes filosóficas modernas mais radicais em termos políticos e religiosos.

Assim, Verney dialoga com as concepções de Ciência emergentes na Eurupa durante o século XVIII e a tradição religiosa, católica, que marca sua formação. Ao mesmo tempo em que o movimento de compreensão dos aspectos internos da obra e de sua relação como o contexto externo de criação permitiu compreender a concepção verneyniana de Ciência.

\section{Referências}

BARBOSA, Mohana Ribeiro. Revolução científica e nascimento da Ciência experimental em Alexandre Koyré. 2013. 110 f. Dissertação (Mestrado) - Curso de Programa de Pós-graduação em História, Universidade Federal de Goiás, Goiânia, 2013. Cap. 01. Disponível em: https://repositorio.bc.ufg.br/tede/bitstream/tde/3031/5/Dissertacao Mohana R Barbosa.pdf . Acesso em: 24 nov. de 2020.

BACON, Francis. Novum Organum ou verdadeiras indicações acerca da interpretação da natureza. Trad. e notas de José Aluysio Reis, Pará de Minas: M\&M Editores, 2003.

CHAUÍ, Marilena. Convite à Filosofia. São Paulo: Ática, 1998.

DESCARTES, René. Discurso sobre o Método. Trad. de J Guinsburg e B. Prado Júnior. São Paulo. Nova Cultural, 1996. (Col. Os Pensadores).

DE ANDRADE, António Alberto Banha. Verney e a projecção de sua obra. Portugal: Instituto de Cultura Portuguesa, 1980.

FERREIRA, Breno Ferraz Leal. Contra todos os inimigos - Luis Antonio Verney: historiografia e método crítico (1736 - 1750). 2009. Dissertação (Mestrado em História Social) - Faculdade de Filosofia, Letras e Ciências Humanas, Universidade de São Paulo, São 
Paulo, 2009. Disponível em: https://www.teses.usp.br/teses/disponiveis/8/8138/tde01122009-110924/pt-br.php. Acesso em: 02 nov. de 2020.

FERREIRA, Breno Ferraz Leal. Economia da Natureza: a História natural entre a Teologia Natural e a Economia Política (Portugal e Brasil 1750-1822). 2016. 233 f. Tese (Doutorado) Curso de História Social, Universidade de São Paulo, São Paulo, 2016. Disponível em: file://C:/Users/Ver\%C3\%B4nica\%20Alves/Downloads/2016_BrenoFerrazLealFerreira_VCo rr.pdf . Acesso em: 24 nov. de 2020.

HENRY, John. A Revolução Científica e as Origens da Ciência Moderna. Trad. de Maria Luíza X. de A. Borges. Rio de Janeiro: Jorge Zahar Editor, 1998. (Ciência e Cultura).

LOCKE, John. Ensaio acerca do entendimento humano. $2^{\mathrm{a}}$ ed. Trad. de Anoar Aiex Opinião. São Paulo: Abril Cultural, 1983. Coleção os Pensadores.

MENDES, Alexandre Claro. O Verdadeiro Método de Estudar: o impasse entre o antigo e o moderno. 2006. 92 f. Dissertação (Mestrado) - Curso de História da Ciência, Universidade de São Paulo, São Paulo, 2006. Disponível em:

https://tede2.pucsp.br/bitstream/handle/13335/1/AlexandreMendes.pdf . Acesso em: 24 nov. de 2020.

OLIVEIRA, Daniel de Lara. Ciência Moderna e Newtonianismo no Projeto Pedagógico de Luis António Verney. 2011. 150 f. Dissertação (Mestrado) - Curso de História Social, Universidade de São Paiulo, São Paulo, 2011. Disponível em:

file:///C:/Users/Ver\%C3\%B4nica\%20Alves/Downloads/2011_DanielDeLaraOliveira_VRev\% 20(2).pdf . Acesso em: 24 nov. 2020.

RUCKSTADTER, Vanessa Campos Mariano. Luis António Verney e o Projeto Pedagógico Modernizador do Reino Português: uma análise do Verdadeiro Método De Estudar (1746). 2012. 263 f. Tese (Doutorado) - Curso de Educação, Universidade Estadual de Maringá, Maringá, 2012. Disponível em: http://www.ppe.uem.br/teses/2012\%20\%20Vanessa\%20Ruckstadter.pdf . Acesso em: 24 nov. de 2020.

SILVA, Iverson Geraldo da. O projeto anti-jesuítico: Verney, os oratorianos e a aliança com o estado português. Sacrilegens, Juiz de Fora, v. 10, n.2, p. 96-108, jul-dez/2013 - Disponível em: http://www.ufjf.br/sacrilegens/files/2014/07/10-2-8.pdf. Acesso em: 24 nov 2020.

VERNEY, L. A. O Verdadeiro Método de Estudar. Vol. 1 (Cartas I-IV). Lisboa: Sá da Costa, 1949.

VERNEY, L. A. O Verdadeiro Método de Estudar. Vol. 2. (Cartas V-VII). Lisboa: Sá da Costa, 1950. 